\title{
Article \\ Greenhouse Gas Abatement in EUROPE-A Scenario-Based, Bottom-Up Analysis Showing the Effect of Deep Emission Mitigation on the European Energy System
}

\author{
Stephan Kigle *(D), Michael Ebner and Andrej Guminski
}

check for

updates

Citation: Kigle, S.; Ebner, M.;

Guminski, A. Greenhouse Gas

Abatement in EUROPE-A

Scenario-Based, Bottom-Up Analysis

Showing the Effect of Deep Emission

Mitigation on the European Energy

System. Energies 2022, 15, 1334.

https://doi.org/10.3390/en15041334

Academic Editors: László Szabó and Gabriella Szajkó

Received: 23 December 2021

Accepted: 8 February 2022

Published: 12 February 2022

Publisher's Note: MDPI stays neutral with regard to jurisdictional claims in published maps and institutional affiliations.

Copyright: (C) 2022 by the authors. Licensee MDPI, Basel, Switzerland. This article is an open access article distributed under the terms and conditions of the Creative Commons Attribution (CC BY) license (https:/ / creativecommons.org/licenses/by/ $4.0 /)$.
FfE Munich, Am Blütenanger 71, 80995 Munich, Germany; mebner@ffe.de (M.E.); aguminski@ffe.de (A.G.) * Correspondence: skigle@ffe.de

\begin{abstract}
Greenhouse gas emissions need to be drastically reduced to mitigate the environmental impacts caused by climate change, and to lead to a transformation of the European energy system. A model landscape consisting of four final energy consumption sector models with high spatial (NUTS-3) and temporal (hourly) resolution and the multi-energy system model ISAaR is extended and applied to investigate the transformation pathway of the European energy sector in the deep emission mitigation scenario solidEU. The solidEU scenario describes not only the techno-economic but also the socio-political contexts, and it includes the EU27 + UK, Norway, and Switzerland. The scenario analysis shows that volatile renewable energy sources (vRES) dominate the energy system in 2050. In addition, the share of flexible sector coupling technologies increases to balance electricity generation from vRES. Seasonal differences are balanced by hydrogen storage with a seasonal storage profile. The deployment rates of vRES in solidEU show that a fast, profound energy transition is necessary to achieve European climate protection goals.
\end{abstract}

Keywords: energy system modelling; multi-energy system; optimization; decarbonization; scenario analysis; final energy consumption; European energy system; European energy transition; renewable energy; electrification

\section{Introduction}

To mitigate the environmental impacts caused by climate change, greenhouse gas (GHG) emissions must be drastically reduced worldwide, leading to a change in energy supply and consumption. However, concrete transformation pathways of the energy systems that achieve such large reductions in GHG emissions are often modeled on a small scale. In Europe, for example, there are numerous scenario analyses at the national level [1]. Even in recent studies [2-5], neighboring European countries are excluded from the analysis.

Nevertheless, an isolated national perspective is short-sighted, and it does not do justice to the complexity of the problem, especially in a highly interconnected energy system such as Europe. A first but insufficient step to take account of the strong interconnection is to include the electrical interdependencies between neighboring countries, such as in [1,6-14]. Nevertheless, a more holistic perspective on the European energy system is needed to consider all the impacts of GHG emission reduction measures.

Approaches to model decarbonization pathways on a European level vary widely. The authors of $[15,16]$ focus on scenarios with $100 \%$ renewables, and [17-27] examine the implications for the design of the energy system in the case of an $80 \%$ to a nearly $100 \%$ reduction in $\mathrm{CO}_{2}$ or $\mathrm{GHG}$ emissions relative to 1990 levels. Reduction targets are realized with a European emissions CAP. Only [23] investigates the effect of multi-objective optimization to minimize system costs while reducing emissions. While a European perspective is necessary to account for system effects, a high spatial resolution is key to account for local differences and constraints. While [15] does not consider regionalization, [18,19,21,22,25,27] 
model energy demand and supply at the national level, with some countries divided into subnational regions. A spatial resolution that deviates from country boundaries and groups countries into larger regions is used in [17,20,24,26]. The author of [23] divides Europe into 87 regions. Equally important is a high temporal resolution as well as the absolute amount of time covered. Here, only $[15,16,23,25,26]$ provide hourly time resolution while $[17-20,24]$ calculate with different time slices of several hours. The authors of $[21,22,27]$ calculate with annual resolution. Of those with hourly resolution, only [26] analyzes a whole year, while the rest analyze several typical days or weeks. In contrast, the model landscape used in this study has both high spatial and temporal resolutions, calculating an entire year.

Therefore, we expanded the FfE model landscape from the national to the European level in the project eXtremOS (Section Funding). The project's main aim was to consistently model European energy system's transformation pathways under extreme regulatory and technological developments to evaluate systemic effects. The model landscape was then applied to calculate an emission mitigation pathway leading to deep GHG emission reduction. The used model landscape consisted of four final energy consumption (FEC) models and the linear optimization multi-energy system model ISAaR (integrated simulation model for unit dispatch and expansion with regionalization) $[11,28]$. The FEC is quantified bottom-up in high spatial (NUTS-3) and temporal (hourly) resolution for the EU27 + UK, Norway and Switzerland $(27+3)$. The modeled FEC sectors are industry, transport, private households, and the tertiary sector. The modeled energy carriers are electricity, (district) heating, hydrogen, gaseous hydrocarbons, liquid hydrocarbons, and biomass. In addition, the provision of $\mathrm{CO}_{2}$ from industrial emissions as feedstock for methanation is considered. In this way, increased sector coupling measures can be taken into account. While FEC sector models are stock and flow models, the cost-optimal transformation pathway of the energy sector is calculated with ISAaR.

However, the energy transition is not solely a techno-economical optimization challenge. If the models and the corresponding results are to support political decision-makers and thus have a positive influence on climate change mitigation, the socio-political context must be considered in addition to technical parameters. The socio-political scenario must therefore fit the quantitative techno-economic target-based scenario.

Besides the high spatial resolution of the FEC sectors, the consideration of multiple energy carriers, and the model endogenous expansion of generation units across Europe, what additionally distinguishes this scenario analysis from the previously mentioned analyses is the integrated scenario process that guarantees a consistent scenario world in terms of techno-economic and socio-political parameters as model inputs [29]. The calculated scenario solidEU represents an ambitious climate change mitigation scenario that includes GHG emission reduction targets of 55\% and 95\% compared to 1990, 2030, and 2050, respectively, as envisaged in the European Commission's Green Deal (COM/2021/550 final). Therefore, the main objective of this study is to quantify the impact of deep GHG emission reductions on the European energy system.

All models and results were developed within the project eXtremOS (Section Funding). Sections 2 and 3 are based on the project's summary report [30], with an additional focus on regional vRES distribution and the hourly unit dispatch in 2050.

\section{Materials and Methods}

\subsection{Model Landscape}

The model landscape deployed for modeling European scenarios at high spatial and temporal resolutions is composed of the four FEC models and a multi-energy system model. The four FEC models are SmInd EU for industry, TraM EU for transport, PriHM EU for households, and TerM EU for the tertiary sector. They are described in detail in [31]. The models provide FEC demand in high spatial (NUTS-3) and in temporal (hourly) resolution. In combination with a detailed potential analysis for volatile renewable energy sources (vRES) [32], the FEC demand serves as input for the multi-energy system model ISAaR. The used weather year is 2012, which represents an average weather year in respect to 
the years between 1980 and 2019 [30]. An overview of the model landscape as well as the interconnections within ISAaR (gray background portion) can be seen in Figure 1.

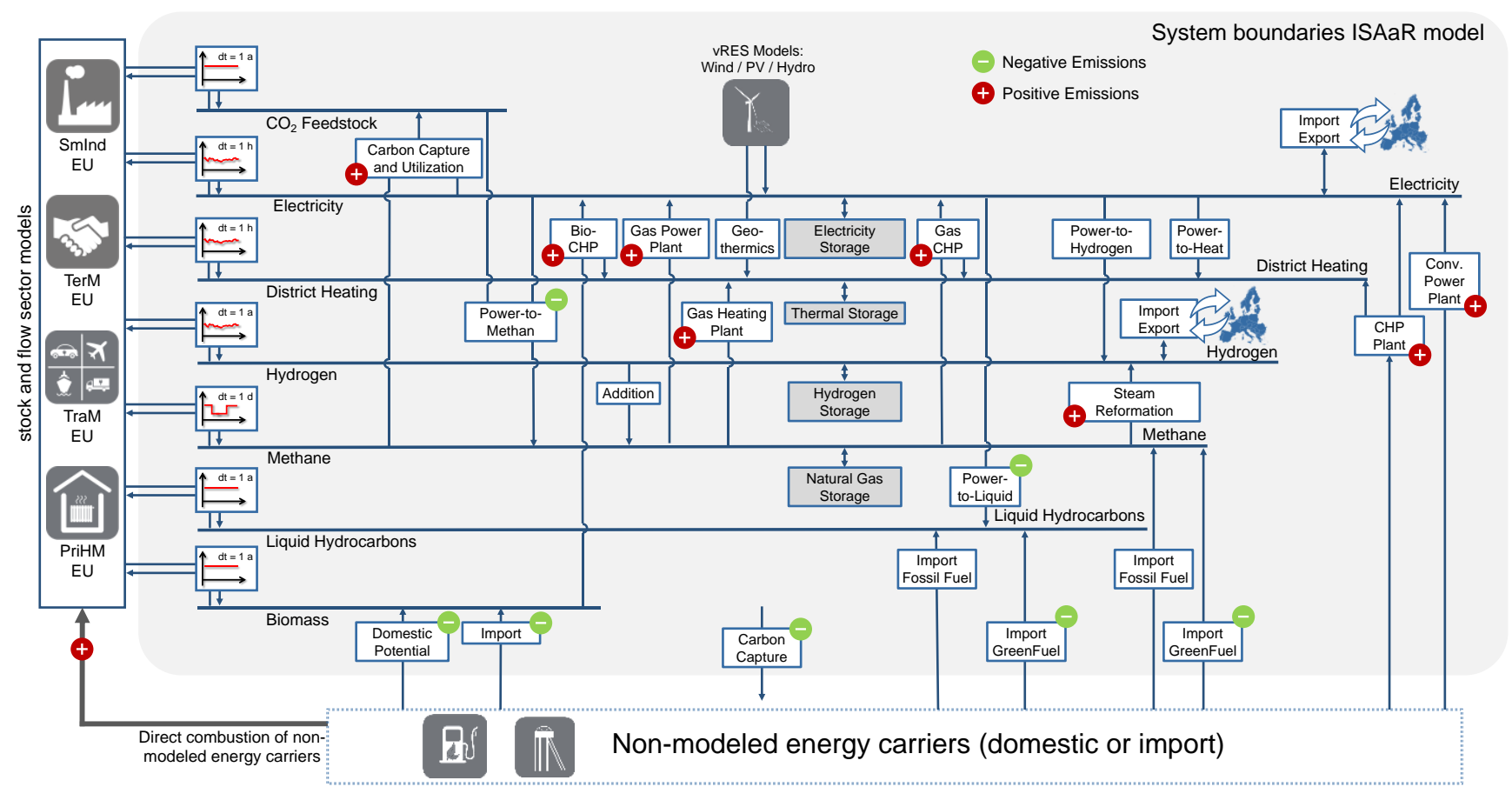

Figure 1. Model landscape and model interconnection as well as generation and sector coupling technologies in ISAaR. Own figure based on $[11,28,30]$.

ISAaR is a linear optimization model using perfect foresight, which minimizes the energy system's total costs. It is a nodes-edges model in hourly resolution with flexible spatial resolution [11,28]. In ISAaR, each energy carrier is modeled as a balance between consumption and generation, the so called "energy carrier balances". The interplay between the energy carrier consumption by the FEC sectors, the energy carrier provision by imports, domestic sources, and renewable energy sources (RES), as well as sector coupling technologies that connect the energy carrier balances among each other, are shown in Figure 1. The mathematical formulation of the optimization problem regarding energy carriers can be found in $[11,28]$. To reduce computation time, the high spatial resolution of the FEC models is reduced in ISAaR. Calculations are conducted on the NUTS-0 level except for the United Kingdom and Denmark, which are further divided into Great Britain and Norther Ireland and into Denmark West and Denmark East. Due to the high resolution vRES potential and the regionalization method, however, it is possible to draw conclusions on the NUTS-3 level regarding installed vRES capacities.

To model the supply side and thus the provision of the energy carriers demanded by the FEC sectors in all modeled regions, ISAaR has been extended, building upon the model framework described in $[11,28]$. The implemented enhancements include the optimization of unit dispatch and expansion in all $27+3$ modeled regions, the ability to exchange hydrogen between modeled regions in addition to electricity, a GHG emissions balance with variable regional resolution, an additional energy carrier balance for $\mathrm{CO}_{2}$ as a feedstock, and a revaluation factor for vRES.

To ensure a continuous evolution of the energy system from 2020 to 2050, information is exchanged between consecutive optimization years. To explain the sequencing, we use the example of the expansion of vRES capacities from 2020 to 2050 in five-year intervals. The year 2020 represents the energy system's status quo and there is no unit expansion. Beginning in 2025, unit expansion is allowed. Newly built units are carried forward to subsequent years based on their technical lifetime. When the projected year of decommissioning is reached, the model then decides whether to rebuild or decommission the units. 
In addition to this mechanism, a minimum level of vRES capacities (vRES capacities of 2020) is assumed until 2050. When these stock units reach their life expectancy, they are always repowered (Figure 2). Apart from stock units, this kind of sequencing is used for all model endogenously built technologies.

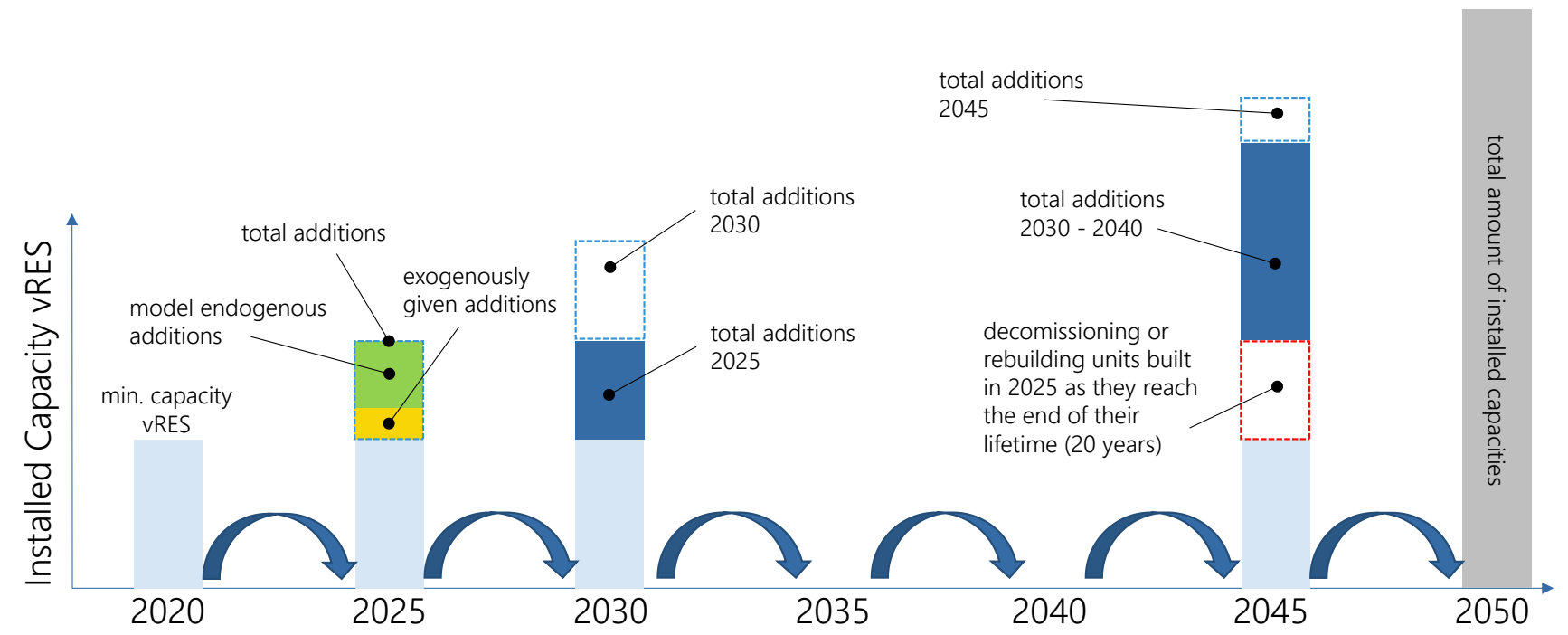

Figure 2. Sequence for vRES additions in ISAaR. Own figure based on $[28,30]$.

This myopic approach, however, leads to uninformed investment decisions [33]. Especially for the expansion of vRES, the risk of stranded investments increases as their cost degression impacts electricity prices. For example, the expansion of generation capacity may pay for itself in one year but not the following. The investment made is therefore not refinanced over the plant's lifetime. To counteract this type of uninformed investment, a revaluation factor is added to the initial investment costs. Future decreasing revenues are anticipated and the difference to the levelized cost of electricity (LCOE) is added to the initial investment costs. This ensures that the investment costs are amortized over the lifetime of the plant. The adapted investment costs $\left(I_{0}{ }^{\prime}\right)$ are calculated as

$$
O=I_{0}^{\prime}-\sum_{t=1}^{n} C_{t} \cdot F L H \cdot(1+i)^{-t},
$$

where $C_{t}$ are the initial LCOEs of the future timesteps $t, F L H$ the full load hours and $i$ the interest rate. The sum over the timesteps runs from one to the end of the technologies' lifetime $n$. With this method, it can be guaranteed that each vRES generation unit built refinances itself during its lifetime, and it is profitable even though the market values for vRES drop.

\subsection{Quantifying the Storyline}

The qualitative scenario framework for solidEU is published in [34], and it was developed using the CIB method [35]. For a better understanding of the results presented in Section 3, key aspects of the solidEU storyline and their influence on the descriptors are outlined below. SolidEU describes a socio-political environment characterized by solidarity in Europe (solidEU). Anthropogenic climate change is fought by all governing institutions with a strong societal mandate, as it is agreed that climate change poses a serious threat to prosperity. National governments are rallying behind an ambitious European policy framework to reduce GHG emissions. Figure 3 shows all descriptors addressed by the solidEU storyline. The "From Word to Value" method is then used to translate the descriptors into quantitative assumptions [29,31]. Descriptors and their influence on modelling decisions and parameters in ISAaR are addressed first. 


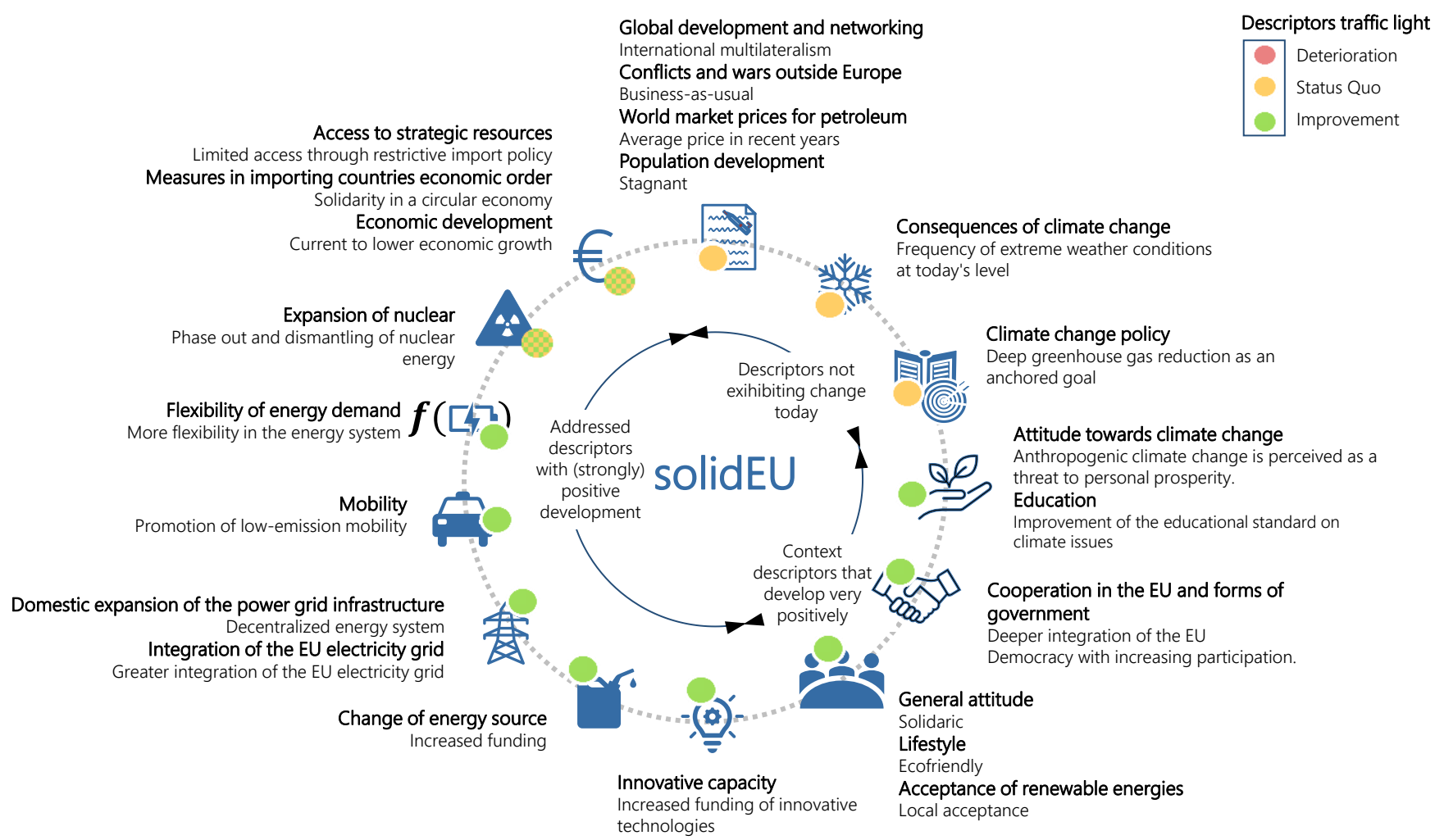

Figure 3. SolidEU scenario descriptors and trends [30].

According to the descriptor "Climate change policy", solidEU represents an ambitious climate change scenario in accordance with current legislative initiatives. Therefore, a reduction target of $95 \%$ of GHG emissions until 2050 from the baseline set in 1990 is assumed. In addition, an interim target of 55\% GHG emission reduction until 2030 compared to 1990 is set as proposed in the European Green Deal (COM/2021/550 final). Using historical data, a GHG CAP for the target years is calculated from the EU GHG inventory [36] and implemented as a boundary condition in ISAaR. In 2050 the CAP amounts to $288 \mathrm{Mt}$ of $\mathrm{CO}_{2}$-equ. The GHG CAPs for the years between 2030 and 2050 are linearly interpolated. While the greatest part of the categories of the EU GHG inventory are explicitly covered by either the FEC models or ISAaR, some categories, e.g., agriculture, remain unaddressed. GHG emissions not covered explicitly in the model landscape are, nevertheless, considered in the GHG CAP. For those GHG emissions, a simplified exogenously specified reduction pathway until 2050 is set. They are reduced by $75 \%$ until 2050 compared to the mean between 2014 and 2018 to account for emission abatement measures, e.g., in agriculture. Emissions covered by one of the models of the model landscape, on the contrary, are included in the optimization as energy and feedstock related $\mathrm{CO}_{2}$ emissions. Emissions are allocated according to the source principle (Figure 1).

According to the descriptor "Cooperation in Europe", only one GHG CAP is set for all $27+3$ regions. No national GHG or sectoral emission targets are considered, as countries cooperate to achieve the GHG targets. This cooperation is further supported by the descriptor "public acceptance of renewable energy," which allows the full potential of vRES in Europe [32] to be exploited without societal constraints. The potential that can be tapped in this way represents the upper limit of vRES expansion in ISAaR.

The descriptor "Interconnection of the European electricity grid" strengthens European electricity market integration. In addition to considering grid expansion projects according to the TYNDP 2020 [37], net transmission capacities (NTCs) between all regions will be increased to $70 \%$ of their thermal capacities from 2030 onwards. This assumption is made following the proposal of the European Commission to increase the NTCs to $75 \%$ of their thermal capacity. NTCs thus increase from 129 GW in 2020 to 637 GW in 2050. 
The descriptor "Expansion of nuclear energy" is only slightly positive, signaling a moderate phase-out of nuclear power generation capacities over time. ISAaR addresses this descriptor by adopting the TYNDP "National Trends" scenario trajectories for nuclear power plants [37]. Between 2040 and 2050, decommissioning trends are extrapolated while commissioning trends are held at 2040 levels. Furthermore, it is assumed that nuclear power plant expansion is prohibited from 2025 onwards. The same methodology applies to coal-fired power plants.

The descriptor "Access to strategic and natural resources from abroad" reviews the influence of the availability of energy carrier imports from outside of Europe. Conditions for importing energy carriers such as gas and oil improve slightly compared to the status quo. This will also lead to the possibility of importing synthetic fuels in the future. However, hydrogen to meet Europe's hydrogen demand is produced exclusively in Europe. Hydrogen can be produced with PEM electrolyzers and traded throughout Europe. The capacity for hydrogen trade between countries is unlimited, but the interconnections between countries are based on the existing natural gas grid [38]. Losses are assumed to be $0.5 \%$ per $100 \mathrm{~km}[39,40]$.

Secondly, the status of the following descriptors (Figure 3) translates into FEC model parameters. Only the main descriptors, beginning with "Demographic development," are described, since not all descriptors and their respective attributions can be addressed in detail. The descriptor "Demographic development" influences the overall development of sector consumption as a function of growing and shrinking populations in Europe [41], and it is called "baseline development" in solidEU. In TraM, for example, this determines the absolute vehicle population; in PriHM the total number of heating systems.

"Innovative capacity of research and enterprises" describes the investment climate for promising technologies and developments in research and companies in the electricity, heat, and transport sectors. In solidEU, this descriptor is characterized by increased subsidies, which has a positive impact on all sectors. In TerM and in PriHM, it favors the replacement rate of fossil heating systems by heat pumps and the coefficient of performance of the latter. In TraM, the descriptor increases, among other factors, the replacement rate of combustion vehicles by battery electric and hydrogen vehicles, and it improves the efficiency of all vehicle classes. In SmInd EU, it facilitates the phase-in of innovative production routes such as electrocrackers for the production of high-value-chemicals. Comparable influences can be addressed to the descriptor "Fuel switching," that summarizes increased measures to promote the electrification of current non-electrified processes and the use of synthetic fuels.

The descriptor "Lifestyle" depicts principles that influence people's ways of living. In solidEU, these can be described as ecofriendly. In TerM and in PriHM, they are not only reflected in the increased exchange rate of heat pumps and the renovation rate but also in decreasing future consumption per capita.

The descriptor "Mobility" means mobility in terms of the amount of environmentally harmful emissions, and it is set to "promotion of low-emission mobility" in solidEU. This impacts the exchange rate of battery electric vehicles and the use of overhead trucks, and it lowers the specific consumption by vehicle class.

"Climate change policy" and "Public acceptance of renewable energy" as described along with the descriptors in the first part of the section, influence the FEC models as well. Specifically, they increase the exchange rates of fossil heating systems and combustion vehicles. In addition, the EU ETS certificate prices are affected by the "climate change policy" descriptor, as it addresses policies and climate protection targets.

In addition to the mentioned descriptors, parameters of the industry model SmInd EU are also affected by the descriptors "world market prices for oil," "economic developmentGDP," and "economic order". These descriptors influence parameters such as production tonnage, gross value added, and the number of businesses developed.

Across all descriptors and model parameters, the matching procedure showed that the degree of detail in the qualitative storyline is insufficient for providing quantification guidance for all relevant model exogenous parameters. Hence, in each sector, additional 
research was performed to quantify parameters such as the starting year for measure implementation for specific process technologies in the industry sector.

\section{Results}

The results are divided into two sections: Section 3.1 addresses the results of the FEC sectors industry, transport, private households, and the tertiary sector. Section 3.2 addresses the results of the energy sector. The analysis will focus on aggregated results for the $27+3$ regions and the distribution of vRES capacities on NUTS-3 level. Resulting datasets for individual countries are publicly available on $[42,43]$ (see Data Availability Statement).

\subsection{FEC Sectors}

The absolute FEC in Europe in solidEU decreases from about 13,200 TWh to about $7800 \mathrm{TWh}$, as shown in Figure 4a. This development is mainly due to efficiency measures as well as direct and indirect electrification. These measures are implemented in all sectors, but the transport sector benefits most. Its FEC can be reduced by about one third. The framework of high innovation readiness in research and development as well as rapid energy source change set by the described descriptors leads to a strong sector coupling. This is most evident in the rapid implementation of battery electric vehicles in passenger and freight transport, application of heat pumps, and innovative industrial processes such as electric steam crackers in high value chemical production or directly reduced iron (DRI) in steel production. The various electrification measures lead to a highly increased electricity consumption. In solidEU, it increases from about $3100 \mathrm{TWh}$ in 2020 to ca. $5000 \mathrm{TWh}$ in 2050, as can be seen in Figure 4b. Here, the rapid decline in the dominant share of fossil fuels, such as oil, coal, and gas, by approximately $65 \%$ of the energy mix from 2020 to 2050 becomes visible. In 2050, only approximately $6 \%$ of fossil fuels (oil, coal, and gas) remain in the final energy mix. The share of hydrogen in the energy mix in 2050 amounts to about $800 \mathrm{TWh}$. In solidEU, hydrogen is used in the industry ( $\sim 500 \mathrm{TWh})$ and in the transport $(10 \%$ and $40 \%$ indirect electrification of cars and heavy trucks in 2050 , respectively) sectors only, representing in total numbers approximately 1.7 million fuel cell trucks and 35 million fuel cell cars by 2050. In the industry sector, hydrogen is used for energy and as a feedstock. A total of 160 TWh of hydrogen is consumed in steel production as feedstock in the DRI process and as a substitute for natural gas in the electric arc furnace. The remaining $\sim 340$ TWh supplies hydrogen burners and CHP plants, and it is used as a substitute natural gas for process heat provision. A total of $80 \%$ of industrial $\mathrm{H}_{2}$ demand is balanced in the industry branches of iron and steel, chemical and petrochemical, and non-ferrous metal and non-metallic minerals.

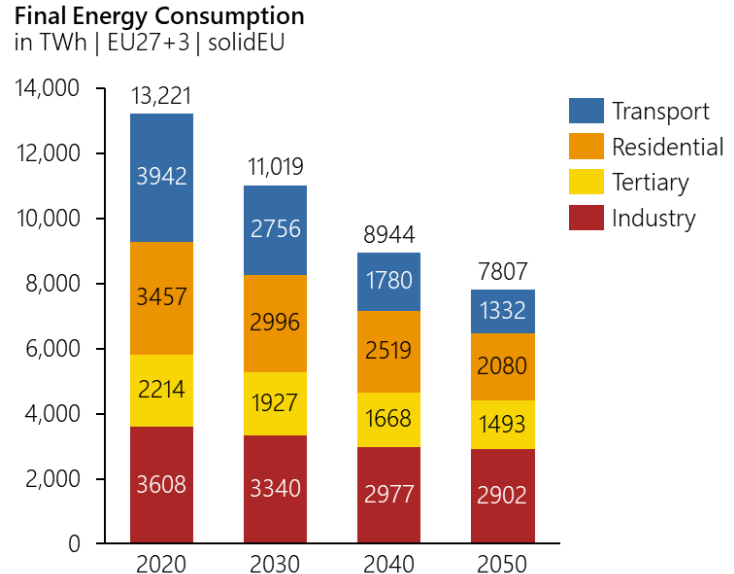

(a)

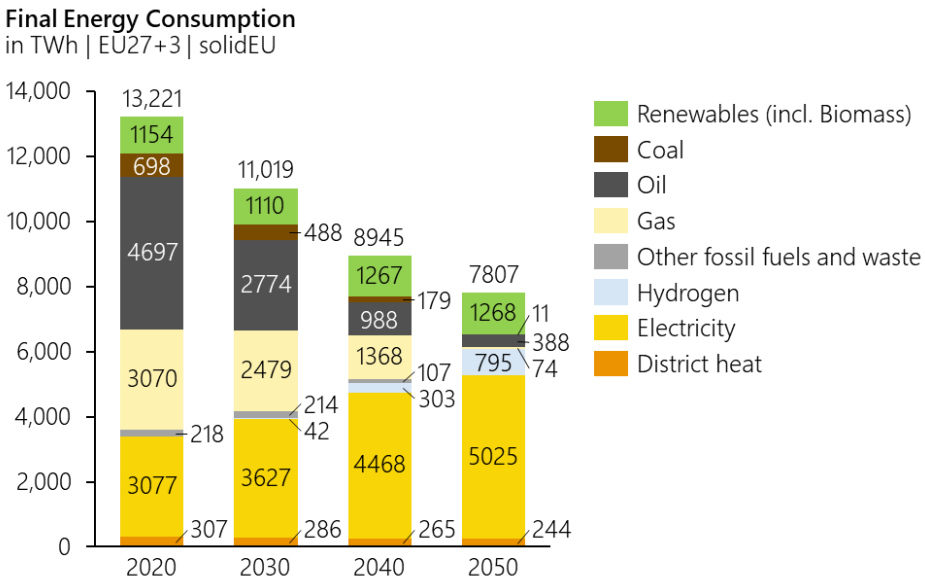

(b)

Figure 4. Development of FEC per sector (a) and energy carrier (b) in Europe [30]. 
To delve deeper into the sector model results, we investigate the private household and the transport sectors in further detail. The main statement of Figure $5 \mathrm{a}$, the share of applications in the FEC, is the sharp decline of space heating share. This can be traced back to increased renovation and efficiency measures in the household sector. The shares of the remaining applications seem to rise, but this is only an effect of the declining space heating share.

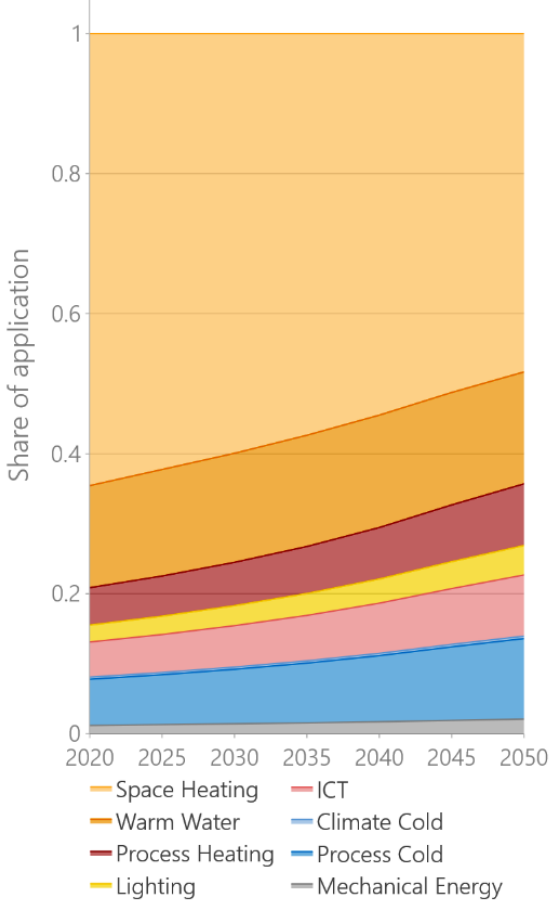

(a)

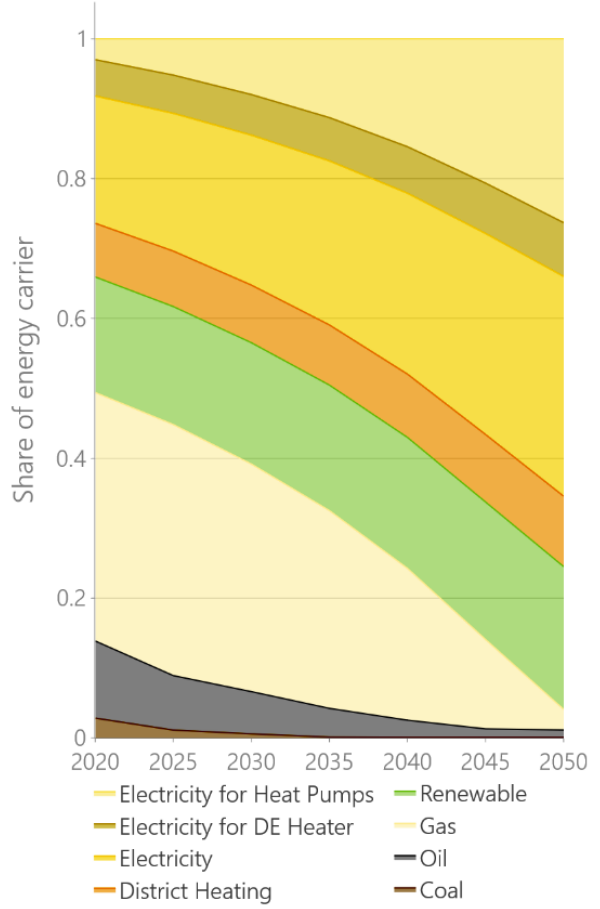

(b)

Figure 5. Share of application (a) and share of energy carriers (b) in the FEC in the private household sector.

Figure $5 \mathrm{~b}$ shows the shares of energy carriers in the FEC in the private household sector. While coal is mainly phased out by 2035 in Europe, miniscule shares of oil and gas remain in the energy mix of 2050. This is due to a small number of fossil heating systems that have not reached their end of life by 2050, but they will be phased out shortly thereafter. The shares of electrical applications in the household sector amount to more than $60 \%$ of the energy mix in 2050. The main driver behind this development is the widespread application of heat pumps in this sector.

In the transport sector, the FEC of passenger cars is reduced by approximately one third until 2050 (Figure 6a). This is partly a result of the shrinking stock of passenger cars in Europe, but it is mainly an effect of increasing efficiency and due to the switch to battery electric vehicles. The second largest impact on the reduction of total FEC can be attributed to heavy lorries and tractors. In this category, $60 \%$ of the vehicle stock in 2050 is powered through direct electrification (battery electric and overhead line). The other $40 \%$ is powered through indirect electrification using hydrogen. Both measures result in a decrease of FEC to about one half from 2020 to 2050 . 


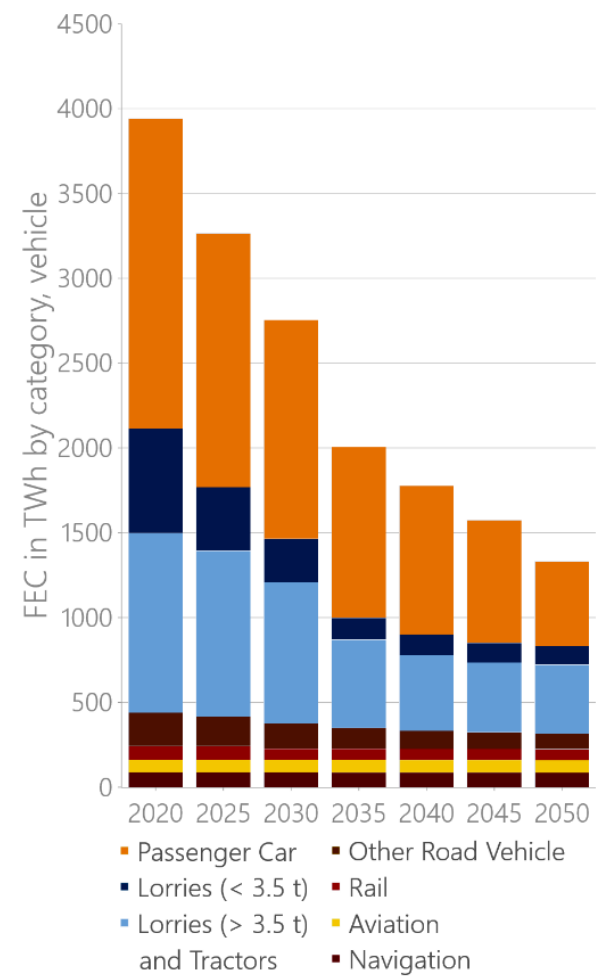

(a)

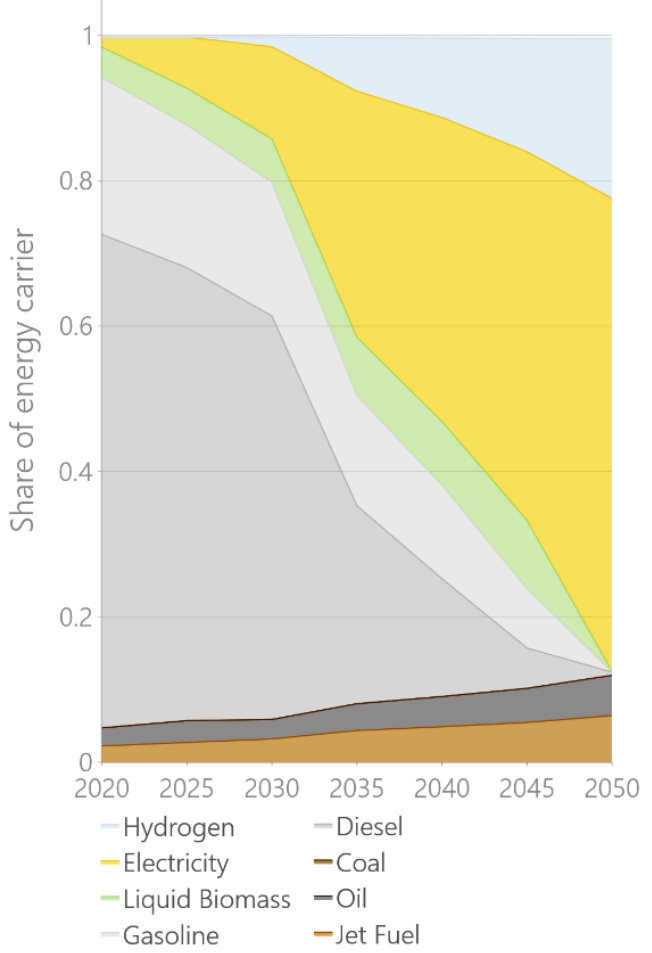

(b)

Figure 6. Share of vehicle category (a) and share of energy carriers (b) in the FEC in the transport sector.

Figure $6 \mathrm{~b}$ shows the shares of energy carriers in the FEC of the transport sector. Diesel and gasoline fade out completely by 2050 due to the replacement of fossil combustion vehicles by battery electric and hydrogen powered vehicles. Hydrogen for fuel cell electric vehicles will not be used until 2030, but it will reach a share of $22 \%$ in the energy mix by 2050. Railways will also be powered through indirect electrification with hydrogen. The biggest share in the energy mix of 2050 will be electricity at approximately 65\%. Europe will see approximately 213 million battery electric passenger cars driving on its roads by 2050. The FEC of aviation and navigation remain steady in solidEU. The shares of jet fuel and oil increase until 2050, but this is a relative effect of shrinking total consumption.

\subsection{Energy Sector}

\subsubsection{Generation Capacities}

As described in Section 3.1, the demand for electricity and hydrogen increases from 2020 to 2050 . The additional demand must be met by the energy sector. In combination with the GHG CAP imposed by the emission targets, this leads to a complete transformation of the energy sector toward RES. While only 417 GW of RES are installed in Europe in 2020 (based on [44]), the installed capacity increases to $3154 \mathrm{GW}$ in 2050. The increase is dominated by additions of vRES capacities as can be seen in Figure 7. The vRES capacities increase 9-fold between 2020 and 2050. Offsite solar power plants register the largest capacity increase. Installed capacity rises from 49 GW in 2020 to 1633 GW in 2050. In second place is onshore wind power whose capacity increases from $176 \mathrm{GW}$ to $856 \mathrm{GW}$. Net additions for offshore wind power amount to $388 \mathrm{GW}$ over the same period. 

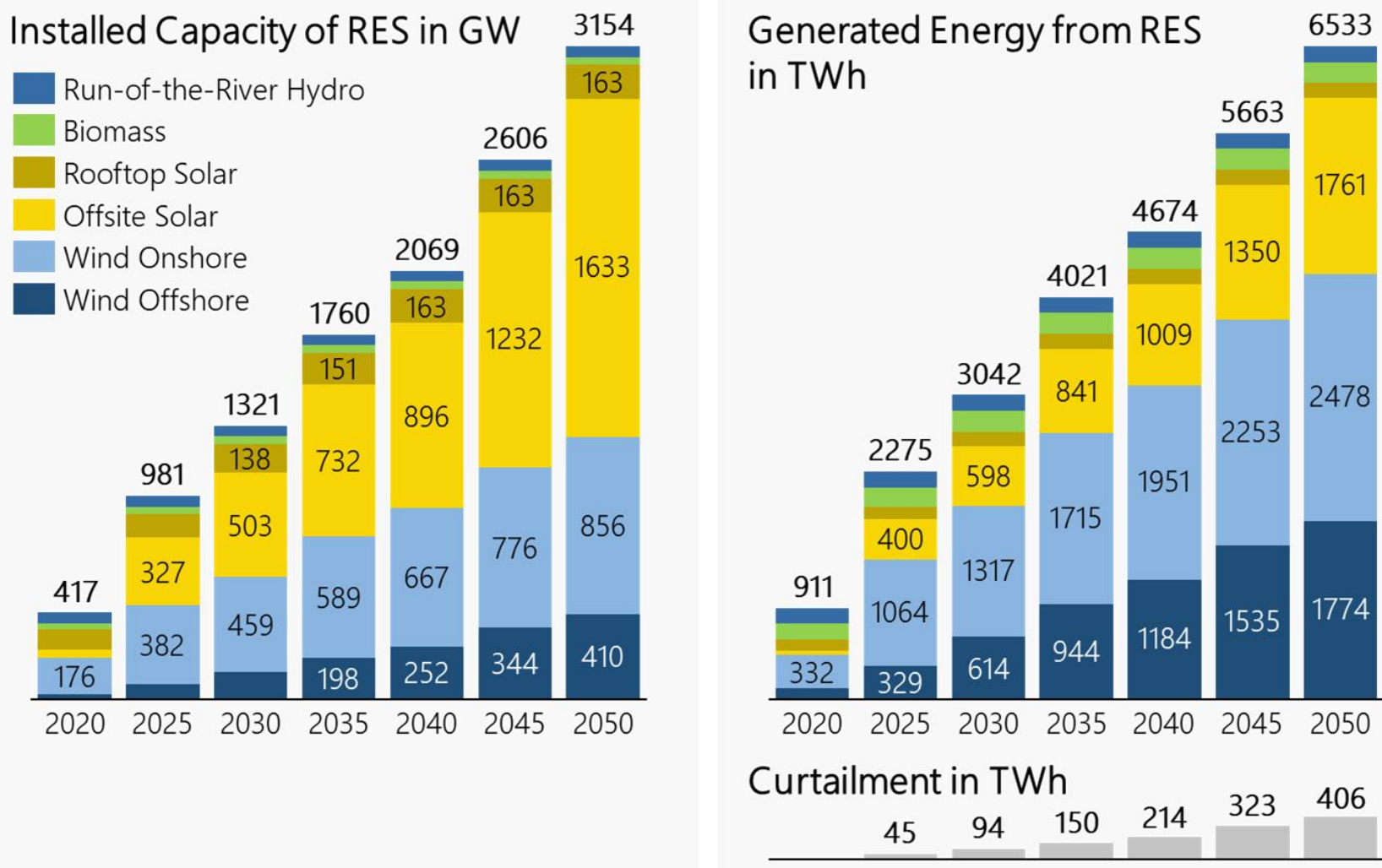

\section{Annual Net Additions of vRES at 20 Years Lifetime}

\section{Renewable Energies Share* on Gross Electricity Consumption}
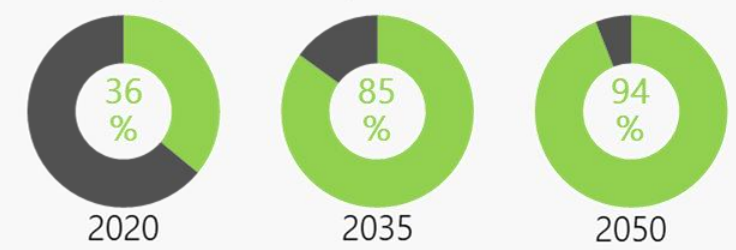

Figure 7. Overview over RES in solidEU [30].

Converted to annual net additions, this means that between 2020 and 2050, an average of $53 \mathrm{GW} / \mathrm{a}$ of PV capacity, $23 \mathrm{GW} /$ a of net onshore wind capacity, and $13 \mathrm{GW} / \mathrm{a}$ of net offshore wind capacity will need to be installed. This would far exceed historic record years for vRES additions. The years with the highest capacity expansions to date are 2011 (PV 21 GW) [45], 2017 (wind onshore 14 GW), and 2019 (wind offshore 9 GW) [46]. Thus, less than half of the required installation rate of solidEU has been achieved in the past. It can therefore be concluded that efforts to increase installation rates for vRES must be intensified to achieve a GHG emission reduction of $-95 \%$ by 2050 compared to 1990 .

As mentioned above, there are two factors that accelerate the expansion of vRES. First, cost reductions combined with an increase in gross electricity consumption of 819 TWh drive the additions until 2030. Only in the following years will the additional increase in gross electricity consumption in combination with the GHG CAP become the main drivers for the further expansion of vRES capacities until 2050.

Figure 8 shows the spatial distribution (NUTS-3) of vRES capacities in Europe in 2050. Most wind offshore capacities are concentrated in the North Sea and the Baltic Sea. Here, electricity production per square kilometer is as high as $65 \mathrm{GWh} / \mathrm{km}^{2}$. The regions with high electricity production from onshore wind power are concentrated in the north of 
Germany, the Netherlands, and the north of France. Here, electricity production per $\mathrm{km}^{2}$ can be as high as $19 \mathrm{GWh}$. The regions with the highest electricity production per $\mathrm{km}^{2}$ for PV can be mainly found in Germany and Italy. However, in most European regions, electricity production per $\mathrm{km}^{2}$ from PV does not exceed $1.2 \mathrm{GWh}$. Compared to the total potential available in solidEU, $53 \%$ of the PV offsite potential, $14 \%$ of the offshore wind potential, and $6 \%$ of the onshore wind potential are developed. This means some countries, such as Germany (91\%) and France (69\%), exploit large amounts of their PV offsite potential.

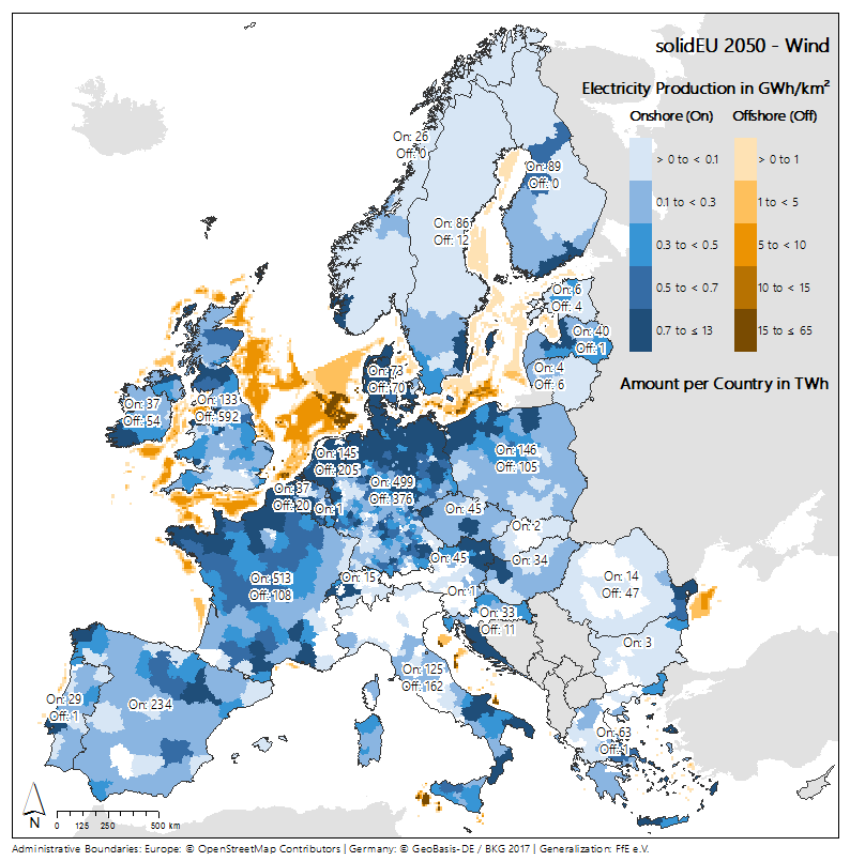

(a)

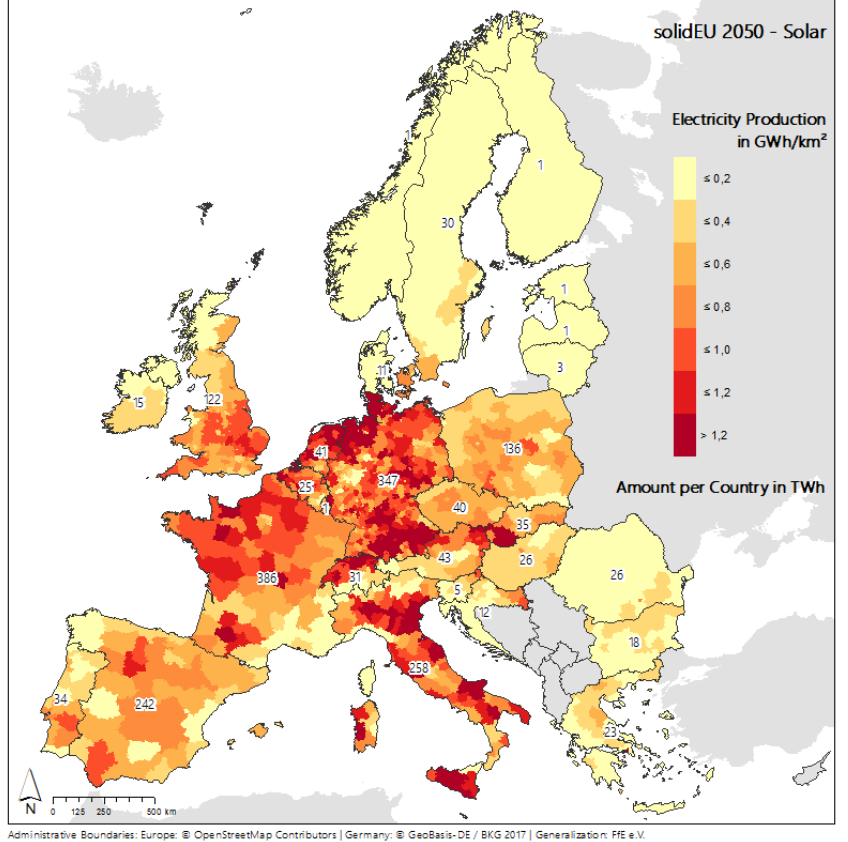

(b)

Figure 8. Regional distribution (NUTS-3) of electricity production per square kilometer in Europe for: (a) on- and off-shore wind capacities; (b) PV capacities. Own figure based on [30]. Differences due to consideration of curtailment of vRES and exclusion of the Balkan countries as they are not relevant for the scope of this scenario.

As large amounts of vRES capacity enter the market, the importance of thermal power plants in power generation declines. While the reduction in installed capacity is only $65 \mathrm{GW}$, the composition as well as the operating characteristics of thermal generation units change fundamentally. While nuclear power plants account for $120 \mathrm{GW}$, coal-fired power plants for $129 \mathrm{GW}$, and gas-fired power plants for $252 \mathrm{GW}$ of the $509 \mathrm{GW}$ of thermal power plants in 2020, in 2050 gas-fired power plants will dominate with $382 \mathrm{GW}$ out of an installed total of $444 \mathrm{GW}$. However, nuclear power plants still play a role with an installed capacity of $51 \mathrm{GW}$, especially since their generation characteristics differ from other thermal generation technologies. As can be seen in Table 1, in 2050, nuclear power plants still generate electricity almost two thirds of the year. For all other technologies, full load hours (FLH) drop to a few hours per year. Due to the emissions CAP, gas fired power plants which run on 407 FLH per year must be fueled with carbon-neutral synthetic methane, which increases their marginal cost. The marginal cost of one MWh of electricity ranges between $€ 150$ and $€ 300$, depending on efficiency. Gas-fired power plants are therefore only used to cover peak load hours. 
Table 1. FLH of thermal power plants per year in solidEU.

\begin{tabular}{cccccccc}
\hline Thermal Power Plants & $\mathbf{2 0 2 0}$ & $\mathbf{2 0 2 5}$ & $\mathbf{2 0 3 0}$ & $\mathbf{2 0 3 5}$ & $\mathbf{2 0 4 0}$ & $\mathbf{2 0 4 5}$ & $\mathbf{2 0 5 0}$ \\
\hline Gas & 3518 & 1346 & 763 & 731 & 715 & 540 & 407 \\
Hard Coal & 2438 & 678 & 585 & 502 & 102 & 43 & 5 \\
Lignite & 4801 & 3591 & 2502 & 2101 & 1328 & 37 & 4 \\
Nuclear & 6899 & 6171 & 5821 & 5897 & 5644 & 5497 & 5547 \\
\hline
\end{tabular}

\subsubsection{Energy Balance Electricity}

As can be seen in Figure 7, the share of RES in gross electricity consumption increases from $36 \%$ in 2020 to $94 \%$ in 2050. In total, RES (including hydroelectric dams, which are not displayed in Figure 7) will generate 6946 TWh of electricity that can be integrated into the market in 2050. Onshore wind accounts for $36 \%$, PV for $28 \%$, and offshore wind for $26 \%$. Curtailment of vRES amounts to 406 TWh.

However, annual electricity generation volumes do not reflect the complexity of a power system dominated by vRES. Since electricity generation depends on variables that cannot be influenced, such as solar radiation or wind, the power system must compensate with more flexibility for inflexible generation to meet demand. Figure 9 shows the hourly European energy balance for electricity, ordered by the annual residual load. The residual load is defined as the electrical load of the FEC sectors minus the electricity generation from RES.

The drastic change in the energy sector described in Section 3.2.1 can also be understood from the annual residual load curve (Figure 9). In 2020, the residual load is positive in $8760 \mathrm{~h}$ of the year. This means that electricity generation from RES is not sufficient to supply all electricity to the European FEC sectors even in a single hour of the year. This changes in 2050 , when the residual load is negative for $6437 \mathrm{~h}$ of the year, meaning more electricity is generated by RES than is demanded by the FEC sectors. The excess electricity is consumed in sector coupling technologies and storages, making the power system more flexible.

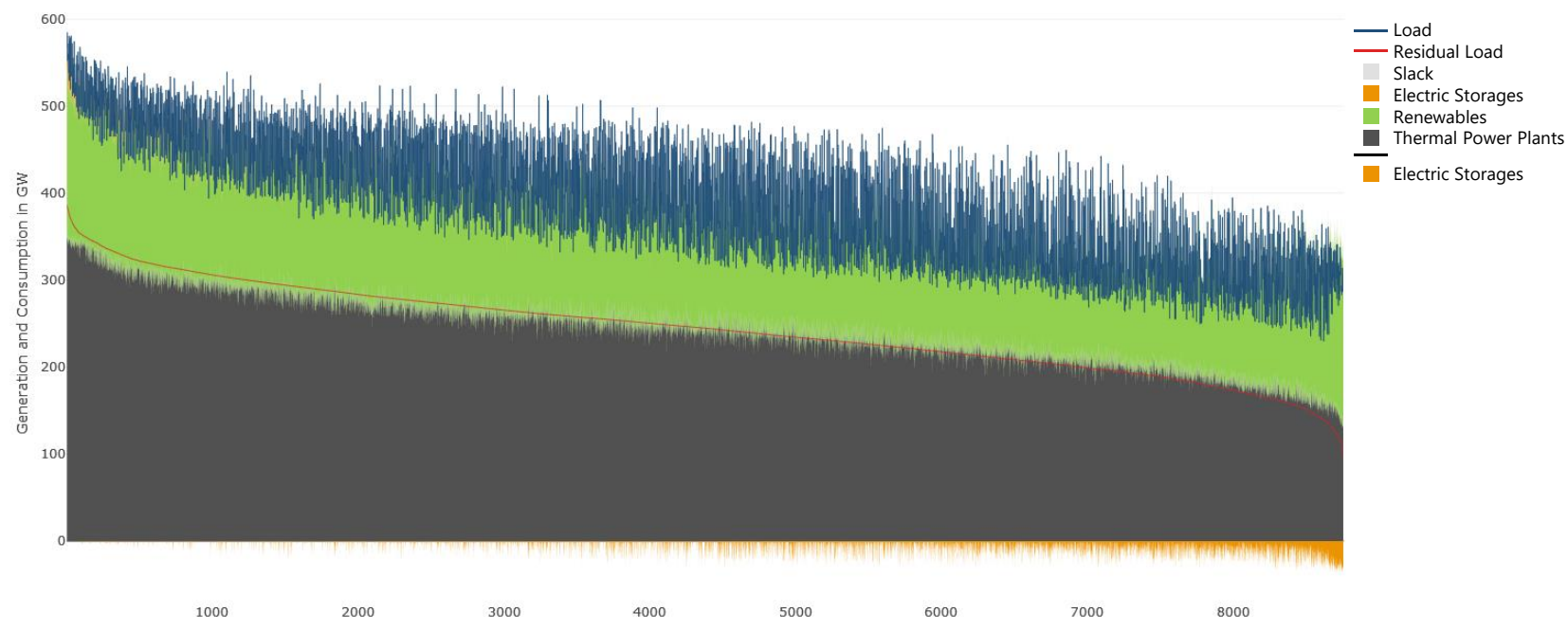

(a)

Figure 9. Cont. 


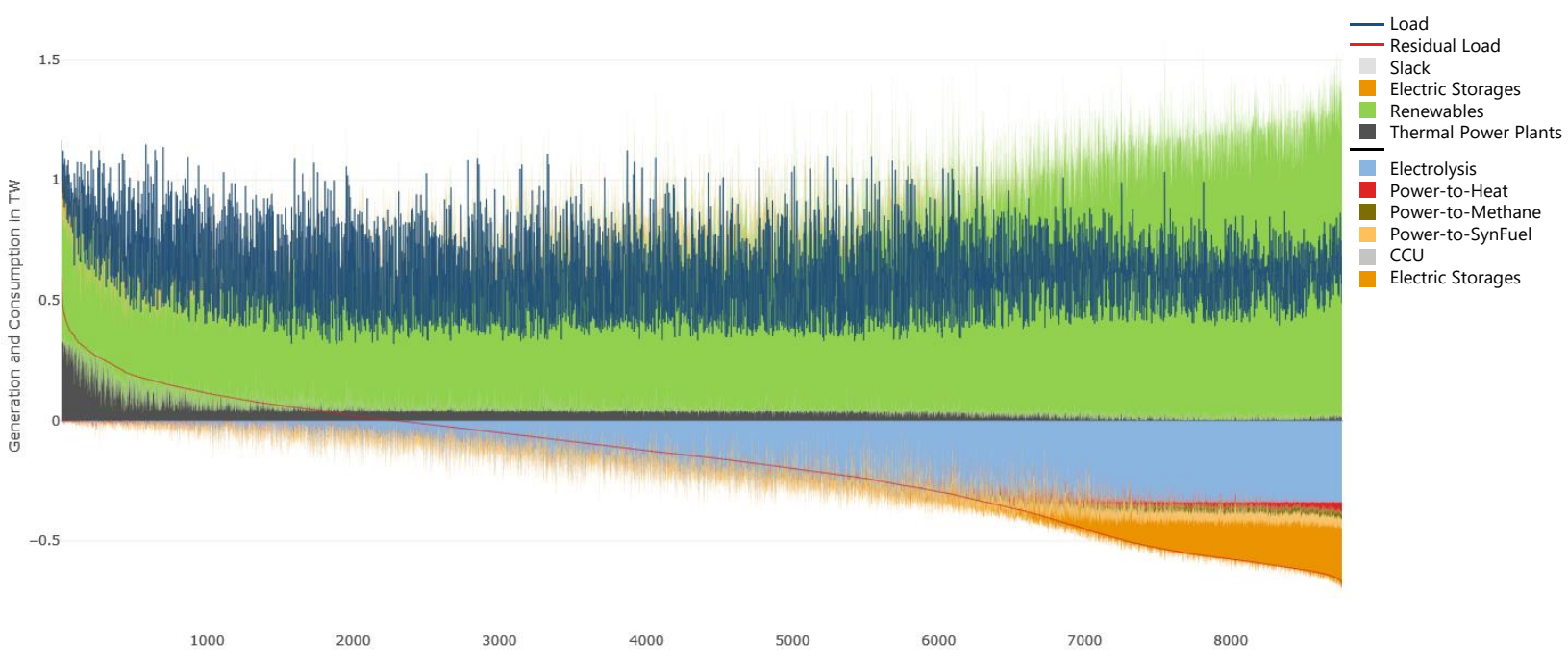

(b)

Figure 9. Hourly European energy balance for electricity ordered by the annual residual load for: (a) the year 2020; (b) the year 2050. Electricity generation is plotted on the positive x-axis, while consumption is plotted in the negative $\mathrm{x}$-axis.

In 2050, with respect to electrical power, a total of $340 \mathrm{GW}$ of electrolysis, $52 \mathrm{GW}$ of power to heat technologies, $29 \mathrm{GW}$ of power to methane, $31 \mathrm{GW}$ of power to synthetic fluid hydrocarbons (SynFuel), and $315 \mathrm{GW}$ of electric storages with a capacity of $1624 \mathrm{GWh}$ are installed. Of the $315 \mathrm{GW}$ electric storages, $246 \mathrm{GW}$ are battery electric storages with a storage capacity of $865 \mathrm{GWh}$. Their dispatch correlates negatively to the residual load. In the hour with the lowest residual load $(-685 \mathrm{GWh} / \mathrm{h})$, the demand technologies add $449 \mathrm{GWh} / \mathrm{h}$ of electricity demand to the electricity demand from the FEC sectors. Electric battery storages additionally add $294 \mathrm{GWh} / \mathrm{h}$. This also corresponds to the maximum load added during the whole year. The maximum electricity demand from the FEC sectors in a single hour is $1164 \mathrm{GWh} / \mathrm{h}$ and the minimum is $316 \mathrm{GWh} / \mathrm{h}$. Additional load from flexible demand technologies and electric storages lies within these extremes and can therefore balance the load efficiently.

Interestingly, even in the hours when the residual load is strongly negative, electricity production from thermal power plants is observed. This behavior is counterintuitive since electricity production from RES is cheaper than from thermal power plants and should therefore be preferred. This indicates RES cannot meet electricity demand in all regions, although from a European perspective, electricity from RES is abundantly available. The reason for this is the NTCs are limited and insufficient to transport the necessary amounts of electricity. This indicates a need for further grid expansion.

Even though NTCs may be the limiting factor in some hours of the year, the European power grid represents great flexibility for the energy system. Overall, the amount of traded electricity increases from 374 TWh in 2020 to 1571 TWh in 2050.

\subsubsection{Hydrogen Generation}

Hydrogen demand in solidEU increases from 149 TWh in 2020 to 1079 TWh in 2050. In addition to the energy use of 795 TWh of hydrogen in the FEC sectors mobility and industry (Section 3.1), 283 TWh are required in the industry sector for feedstock consumption. To supply the FEC sectors with hydrogen, a total of $340 \mathrm{GW}$ of electrolysis capacity is necessary. Electrolyzers run on an average of $5431 \mathrm{FLH}$ and hydrogen is mainly produced from RES as can be seen in Figure 9.

Hydrogen is, therefore, mainly produced during periods of low demand from the FEC sectors and high availability of vRES. To provide hydrogen throughout the year, it must be stored as no hydrogen imports are allowed (Section 2). The storage profile of a fictional 
European hydrogen storage facility is shown in Figure 10, where a clear seasonal profile can be seen. While the hydrogen storage is emptied in the winter months, it is filled in summer and fall. A total storage volume of $170 \mathrm{TWh}$ is required. A hydrogen storage facility thus compensates for seasonal differences in power generation and enables higher integration of vRES into the energy system. However, this finding needs to be solidified in future research with the implementation of real hydrogen storage technologies and potentials.

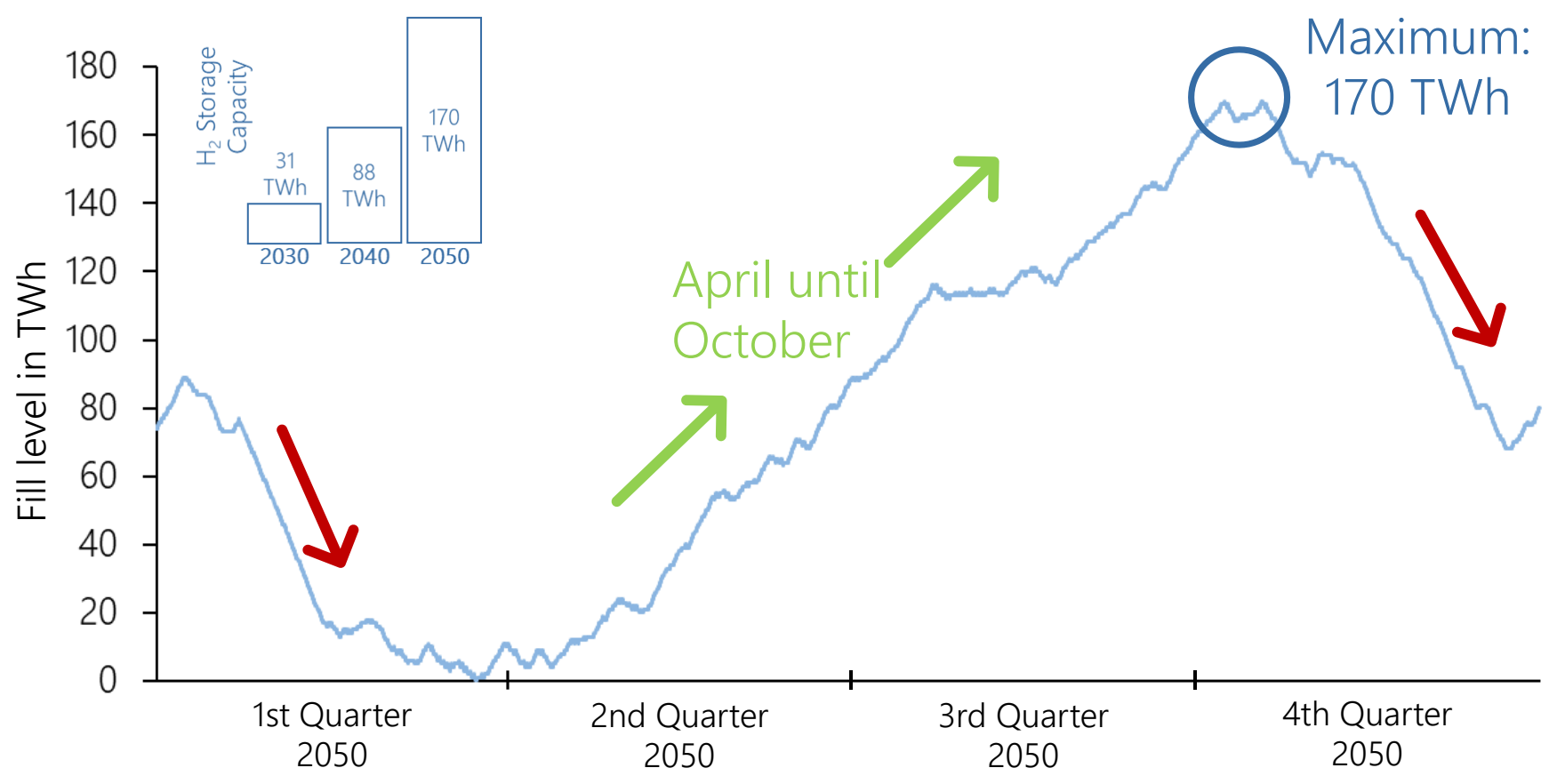

Figure 10. Annual fill level of a hypothetical European hydrogen storage in 2050 as well as maximum storage capacities for the years 2030, 2040, and 2050.

\section{Discussion}

The results show that far-reaching emission reduction targets supported by a solidaritybased European community have a strong impact on the composition and the level of the FEC, as well as on energy supply. Of crucial importance for the transformation of the energy system is the expansion of vRES.

Looking at the composition of the FEC, solidEU clearly identifies as a strong electrification scenario. Combining qualitative and quantitative scenario construction in the integrated scenario process reveals the sociopolitical aspects which drive technology implementation and therefore influence FEC. The underlying storyline adds meaning to parameter quantifications and allows the reader to understand how societal developments facilitate important parameters such as technology implementation rates. This is a consideration that is often neglected when creating different scenarios from a technical point of view, e.g., electrification vs. green gases. Further research, however, is needed regarding FEC sectors other than industry, transport, private households, and the tertiary sector. The development of sectors, such as transformation or agriculture, have only been modeled in a stylized way and require further investigation in the future.

The first main finding of the results presented is the European vRES potentials are sufficient to meet the increase in gross electricity consumption, even in a strong electrification scenario. Even with the constraint that European hydrogen demand is produced only in Europe, not all the potential is realized. On- and off-shore wind potential, especially, remain abundantly available. Required net annual addition of vRES capacities to meet the GHG emission target of $-95 \%$ in 2050 compared to 1990, however, are significantly higher than the historical record addition $[45,46]$. Efforts to accelerate the expansion of vRES capacities must therefore be enforced in order to reach emissions reduction targets that are also in 
accordance with the European Green Deal and "Fit for 55" (COM/2021/550 final). This is all the truer as it is likely that there will be a slow ramp-up phase of installation capacities, which will lead to higher installation rates at a later date. The annual peak values for the installation of vRES could therefore be significantly higher in practice. While according to their national long-term strategies there are six countries (Austria, Denmark, France, Germany, Italy, and Sweden) considered to be pace-setting regarding the implementation of the European climate targets, Bulgaria, Croatia, Latvia and Poland are considered to be foot-dragging [47]. Since it is difficult to achieve climate targets even in Europe based on solidarity, as in solidEU, it is even more important that all European countries are convinced of the necessity to restructure their energy provision. One possibility for achieving this goal and simultaneously boosting the expansion of RES could be a large-scale subsidization of RES by the EU for all member countries.

The second main finding relates to the necessary flexibility of the energy system to integrate additional vRES electricity generation. Besides small amounts of power to heat, power to methane, and power to SynFuel, flexibility is provided by electrical storages as well as hydrogen production and hydrogen storage. While electric storages cover short term fluctuations, hydrogen storages balance seasonal differences. The strong reinforcement of European NTCs additionally compensates for regional generation differences. This shows that a stronger coupling of electricity markets is necessary. Increasing the NTCs from $70 \%$ to $75 \%$ of their thermal capacities could be a viable way forward in the short term, especially since this measure could be implemented without the often time-consuming construction of new power grids. In total, the European energy systems need to become more flexible.

Quantitative statements on the degree of flexibility, however, are difficult as only one weather year was simulated in this scenario analysis, which means quantitative parameters may not be robust. Nevertheless, the qualitative conclusion that the degree of flexibility in the European energy system must increase in the future remains robust. This is even truer considering that the weather year used, 2012, represents an average weather year in terms of the years between 1980 and 2019. In more extreme weather years, the need for even higher degrees of flexibility is very likely. Another limitation is the neglect of the power grid itself. No grid calculations were performed; therefore, no conclusions can be made about the ability of the power grid to distribute the additional electricity. Further research is needed as the actual grid can limit the flexibility of the power system.

Further research is also needed regarding hydrogen production and storage. As explained in Section 2.1, a hypothetical ideal European hydrogen storage mechanism with infinite storage capacity was assumed. In the future, real hydrogen storage potentials, import capacities, and re-electrification must be considered to get a more realistic few of the role of hydrogen in the European energy system, especially as the discussion about importing hydrogen from outside Europe gains momentum. Here, it could be interesting to show that European hydrogen production can improve the integration of vRES electricity generation into the power system and balance seasonal generation variations.

\section{Conclusions}

To analyze the European energy system, a model landscape consisting of four FEC models and the multi-energy system model ISAaR was developed and extended to the EU27 + UK, Norway, and Switzerland. The high spatial (NUTS-3) and temporal (hourly) resolutions allow systemic effects to be investigated both at the European level and at the regional level for all hours of a year.

The model landscape was then used to investigate the impact of the deep GHG mitigation scenario, solidEU, on the European energy sector. The FEC was found to decrease by 5400 TWh from 2020 to 2050 mainly due to electrification measures. In 2050, electricity accounts for two thirds of the FEC, while hydrogen accounts for one tenth. While complying with GHG emission targets, the energy sector must change significantly to meet FEC demand, as well as electricity demand from sector coupling technologies such 
as hydrogen, power to heat, power to methane and power to SynFuel. In the year 2050, the energy sector is dominated by vRES in the solidEU scenario. Installed capacities of onshore wind, offshore wind, and PV amount to more than $3000 \mathrm{GW}$, generating more than 6000 TWh of electricity. In 2050, in combination with other RES, they cover $94 \%$ of the gross electricity consumption.

The amount of additional vRES capacity installed thereby exceeds historic record years. This means that major efforts in expanding vRES capacities are needed to meet GHG emission targets of -95\% compared to 1990 in Europe. Considering the realization of the European Commission's Green Deal (COM/2021/550 final) this means all European countries must accelerate vRES installations. One possibility for achieving this goal may be a large-scale subsidization of RES by the EU.

To balance the volatile electricity production from vRES, the energy system must increase its flexibility by adding battery electric storages and sector coupling technologies. Here, hydrogen can play an important role to compensate for seasonal generation fluctuations. Hydrogen storages can be filled during times of high electricity production from vRES while electricity demand from the FEC sectors is low, which is mainly the case between April and October. In the winter months, the storages can then be emptied.

In summary, in a solidary Europe as outlined in the solidEU scenario, a deep decarbonization of the energy system can be achieved. In reality, however, this will require an enormous effort.

Author Contributions: Conceptualization, S.K. and A.G.; methodology, software, validation, formal analysis, and data curation and visualization regarding the multi-energy system model ISAaR, S.K.; methodology, software, validation, formal analysis, and data curation and visualization regarding the FEC models, A.G. and M.E.; writing - sections: introduction, model landscape, energy sector, S.K., sections on FEC sectors: M.E. and A.G., sections on quantifying the storyline and discussion: S.K., M.E. and A.G.; review and edition, A.G., M.E. and S.K. All authors have read and agreed to the published version of the manuscript.

Funding: This research was conducted as part of the eXtremOS project, which is supported by the German Federal Ministry for Economic Affairs and Energy under grant no. 03ET4062A/B. The responsibility for the content lies solely with the authors.

Data Availability Statement: The resulting datasets for FEC demands on NUTS-3 and NUTS-0 level are available at http:/ / opendata.ffe.de/project/extremos/ (accessed on 1 February 2022). The energy balances for all modeled energy carriers, emissions per sector, installed capacities for RES and thermal power plants, and energy flows for electricity and hydrogen for all modeled countries are available at http:/ / isaarblick.ffe.de/ (accessed on 1 February 2022). Additional information on the project eXtremOS can be found at https:/ / extremos.ffe.de/ (accessed on 1 February 2022).

Acknowledgments: Special thanks go to Claudia Fiedler, Alexander Murmann, Timo Limmer, Tobias Schmid, Fabian Jetter, Steffen Fattler, Christoph Pellinger and Simon Pichlmaier who made this paper possible through their work on input data, model implementations, and administrative support.

Conflicts of Interest: The authors declare no conflict of interest.

\section{References}

1. Borasio, M.; Moret, S. Deep Decarbonisation of Regional Energy Systems: A Novel Modelling Approach and Its Application to the Italian Energy Transition. Renew. Sustain. Energy Rev. 2022, 153, 111730. [CrossRef]

2. Fortes, P.; Simoes, S.G.; Gouveia, J.P.; Seixas, J. Electricity, the Silver Bullet for the Deep Decarbonisation of the Energy System? Cost-Effectiveness Analysis for Portugal. Appl. Energy 2019, 237, 292-303. [CrossRef]

3. Prina, M.G.; Lionetti, M.; Manzolini, G.; Sparber, W.; Moser, D. Transition Pathways Optimization Methodology through EnergyPLAN Software for Long-Term Energy Planning. Appl. Energy 2019, 235, 356-368. [CrossRef]

4. Hansen, K.; Mathiesen, B.V.; Skov, I.R. Full Energy System Transition towards 100\% Renewable Energy in Germany in 2050. Renew. Sustain. Energy Rev. 2019, 102, 1-13. [CrossRef]

5. Lanati, F.; Gaeta, M. How to Achieve a Complete Decarbonization of the Italian Energy System by 2050? In Proceedings of the 2020 17th International Conference on the European Energy Market (EEM), Stockholm, Sweden, 16-18 September 2020; pp. 1-5.

6. Antosiewicz, M.; Nikas, A.; Szpor, A.; Witajewski-Baltvilks, J.; Doukas, H. Pathways for the Transition of the Polish Power Sector and Associated Risks. Environ. Innov. Soc. Transit. 2020, 35, 271-291. [CrossRef] 
7. Bompard, E.; Botterud, A.; Corgnati, S.; Huang, T.; Jafari, M.; Leone, P.; Mauro, S.; Montesano, G.; Papa, C.; Profumo, F. An Electricity Triangle for Energy Transition: Application to Italy. Appl. Energy 2020, 277, 115525. [CrossRef]

8. Limpens, G.; Moret, S.; Jeanmart, H.; Maréchal, F. EnergyScope TD: A Novel Open-Source Model for Regional Energy Systems. Appl. Energy 2019, 255, 113729. [CrossRef]

9. Limpens, G.; Jeanmart, H.; Maréchal, F. Belgian Energy Transition: What Are the Options? Energies 2020, 13, 261. [CrossRef]

10. Bartholdsen, H.-K.; Eidens, A.; Löffler, K.; Seehaus, F.; Wejda, F.; Burandt, T.; Oei, P.-Y.; Kemfert, C.; Hirschhausen, C. von Pathways for Germany's Low-Carbon Energy Transformation Towards 2050. Energies 2019, 12, 2988. [CrossRef]

11. Böing, F.; Regett, A. Hourly $\mathrm{CO}_{2}$ Emission Factors and Marginal Costs of Energy Carriers in Future Multi-Energy Systems. Energies 2019, 12, 2260. [CrossRef]

12. Lombardi, F.; Pickering, B.; Colombo, E.; Pfenninger, S. Policy Decision Support for Renewables Deployment through Spatially Explicit Practically Optimal Alternatives. Joule 2020, 4, 2185-2207. [CrossRef]

13. Landis, F.; Marcucci, A.; Rausch, S.; Kannan, R.; Bretschger, L. Multi-Model Comparison of Swiss Decarbonization Scenarios. Swiss J. Econ. Stat. 2019, 155, 12. [CrossRef]

14. Müller, C.; Falke, T.; Hoffrichter, A.; Wyrwoll, L.; Schmitt, C.; Trageser, M.; Schnettler, A.; Metzger, M.; Huber, M.; Küppers, M.; et al. Integrated Planning and Evaluation of Multi-Modal Energy Systems for Decarbonization of Germany. Energy Procedia 2019, 158, 3482-3487. [CrossRef]

15. Connolly, D.; Lund, H.; Mathiesen, B.V. Smart Energy Europe: The Technical and Economic Impact of One Potential 100\% Renewable Energy Scenario for the European Union. Renew. Sustain. Energy Rev. 2016, 60, 1634-1653. [CrossRef]

16. Zappa, W.; Junginger, M.; van den Broek, M. Is a 100\% Renewable European Power System Feasible by 2050? Appl. Energy 2019, 233-234, 1027-1050. [CrossRef]

17. Hainsch, K.; Burandt, T.; Kemfert, C.; Löffler, K.; Oei, P.-Y.; von Hirschhausen, C. Emission Pathways Towards a Low-Carbon Energy System for Europe: A Model-Based Analysis of Decarbonization Scenarios; Social Science Research Network: Rochester, NY, USA, 2018.

18. Spiecker, S.; Weber, C. The Future of the European Electricity System and the Impact of Fluctuating Renewable Energy-A Scenario Analysis. Energy Policy 2014, 65, 185-197. [CrossRef]

19. Simoes, S.; Nijs, W.; Ruiz, P.; Sgobbi, A.; Thiel, C. Decarbonised Pathways for a Low Carbon EU28 Power Sector until 2050. In Proceedings of the 11th International Conference on the European Energy Market (EEM14), Krakow, Poland, 28-30 May 2014; pp. 1-5.

20. Solano Rodriguez, B.; Drummond, P.; Ekins, P. Decarbonizing the EU Energy System by 2050: An Important Role for BECCS. Clim. Policy 2017, 17, S93-S110. [CrossRef]

21. Capros, P.; Tasios, N.; De Vita, A.; Mantzos, L.; Paroussos, L. Model-Based Analysis of Decarbonising the EU Economy in the Time Horizon to 2050. Energy Strategy Rev. 2012, 1, 76-84. [CrossRef]

22. Capros, P.; Paroussos, L.; Fragkos, P.; Tsani, S.; Boitier, B.; Wagner, F.; Busch, S.; Resch, G.; Blesl, M.; Bollen, J. European Decarbonisation Pathways under Alternative Technological and Policy Choices: A Multi-Model Analysis. Energy Strategy Rev. 2014, 2, 231-245. [CrossRef]

23. Louis, J.-N.; Allard, S.; Kotrotsou, F.; Debusschere, V. A Multi-Objective Approach to the Prospective Development of the European Power System by 2050. Energy 2020, 191, 116539. [CrossRef]

24. Haller, M.; Ludig, S.; Bauer, N. Decarbonization Scenarios for the EU and MENA Power System: Considering Spatial Distribution and Short Term Dynamics of Renewable Generation. Energy Policy 2012, 47, 282-290. [CrossRef]

25. Jägemann, C.; Fürsch, M.; Hagspiel, S.; Nagl, S. Decarbonizing Europe's Power Sector by 2050-Analyzing the Economic Implications of Alternative Decarbonization Pathways. Energy Econ. 2013, 40, 622-636. [CrossRef]

26. Pleßmann, G.; Blechinger, P. Outlook on South-East European Power System until 2050: Least-Cost Decarbonization Pathway Meeting EU Mitigation Targets. Energy 2017, 137, 1041-1053. [CrossRef]

27. Capros, P.; Kannavou, M.; Evangelopoulou, S.; Petropoulos, A.; Siskos, P.; Tasios, N.; Zazias, G.; DeVita, A. Outlook of the EU Energy System up to 2050: The Case of Scenarios Prepared for European Commission's "Clean Energy for All Europeans" Package Using the PRIMES Model. Energy Strategy Rev. 2018, 22, 255-263. [CrossRef]

28. Fattler, S.; Conrad, J.; Regett, A.; Böing, F.; Guminski, A.; Greif, S. (Eds.) Dynamis-Hauptbericht: Dynamische und intersektorale Maßnahmenbewertung zur kosteneffizienten Dekarbonisierung des Energiesystems; Forschungsstelle für Energiewirtschaft e.V.: München, Germany, 2019; ISBN 978-3-941802-45-2.

29. Guminski, A.; Pellinger, C.; von Roon, S.; Fiedler, C. Vom Wort Zum Wert-Leitfaden Zur Quantifizierung von Kontextszenarien Für Komplexe Modelllandschafte. Energ. Tagesfr. 2020, 4, 35-39.

30. Guminski, A.; Fiedler, C.; Kigle, S.; Pellinger, C.; Dossow, P.; Ganz, K.; Jetter, F.; Kern, T.; Limmer, T.; Murmann, A.; et al. EXtremOS Summary Report: Modeling Kit and Scenarios for Pathways Towards a Climate Neutral Europe; Forschungsstelle für Energiewirtschaft e.V.: Munich, Germany, 2021. [CrossRef]

31. Fiedler, C.; Guminski, A.; Limmer, T.; Wagner, T.; Bilici, S.; Pellinger, C.; von Roon, S. Modelling Transformation Pathways for EU27+3 Final Energy Demand Using Temporally and Spatially Resolved Sector Models. In Proceedings of the 5th AIEE Energy Symposium, Virtual Conference, 15-17 December 2020; pp. 187-235.

32. Ebner, M.; Fiedler, C.; Jetter, F.; Schmid, T. Regionalized Potential Assessment of Variable Renewable Energy Sources in Europe. In Proceedings of the 2019 16th International Conference on the European Energy Market (EEM), Ljubljana, Slovenia, 18-20 September 2019; pp. 1-5. 
33. Poncelet, K.; Delarue, E.; Six, D.; D'haeseleer, W. Myopic Optimization Models for Simulation of Investment Decisions in the Electric Power Sector. In Proceedings of the 2016 13th International Conference on the European Energy Market (EEM), Porto, Portugal, 6-9 June 2016; pp. 1-9.

34. Ezequiel, D.; Poganietz, W.-R. Storylines for Extreme Context Energy Scenarios for Germany and Neighbouring Countries. 2020.

35. Weimer-Jehle, W. Cross-Impact Balances: A System-Theoretical Approach to Cross-Impact Analysis. Technol. Forecast. Soc. Change 2006, 73, 334-361. [CrossRef]

36. National Emissions Reported to the UNFCCC and to the EU Greenhouse Gas Monitoring Mechanism-European Environment Agency. Available online: https:/ / www.eea.europa.eu/data-and-maps/data/national-emissions-reported-to-the-unfccc-andto-the-eu-greenhouse-gas-monitoring-mechanism-16 (accessed on 26 November 2021).

37. Lebois, O.; Boersma, P.; McGowan, D.; Rzepczyk, T.; Sönmez, C.; Powell, D.; Fernandez, M.; Bogucka, M.; Watine, L.; Nielsen, M. TYNDP 2020-Scenario Report; ENTSO-E: Brussels, Belgium, 2020.

38. The European Natural Gas Network 2017; ENTSOG: Brussels, Belgium, 2017.

39. Krieg, D. Konzept und Kosten Eines Pipelinesystems zur Versorgung des Deutschen Straßenverkehrs mit Wasserstoff; Schriften des Forschungszentrums Jülich Reihe Energie \& Umwelt; Forschungszentrum Jülich: Jülich, Germany, 2012; ISBN 978-3-89336-800-6.

40. Bossel, U.; Eliasson, B.; Taylor, G. The Future of the Hydrogen Economy: Bright or Bleak? Cogener. Distrib. Gener. J. 2003, 18, 29-70. [CrossRef]

41. Population on 1 January by Age Group, Sex and NUTS 3 Region-Products Datasets-Eurostat. Available online: https:/ / ec.europa. eu/eurostat/web/products-datasets/product?code=demo_r_pjangrp3 (accessed on 26 November 2021).

42. Opendata.Ffe.de-The FfE Open Data Portal. Available online: http:/ / opendata.ffe.de/ (accessed on 26 November 2021).

43. ISAaR Dashboard. Available online: http:/ / isaarblick.ffe.de/ (accessed on 26 November 2021).

44. IRENA. Renewable Capacity Statistics 2020; International Renewable Energy Agency (IRENA): Masdar City, Abu Dhabi, 2020; ISBN 978-92-9260-239-0.

45. Schmela, M. EU Market Outlook for Solar Power 2020-2024; SolarPower Europe: Brussels, Belgium, 2020; ISBN 978-94-6407-347-8.

46. Komusanac, I.; Brindley, G.; Fraile, D.; Ramirez, L. Wind Energy in Europe 2020 Statistics and the Outlook for 2021-2025; Wind Europe: Brussels, Belgium, 2021.

47. Maris, G.; Flouros, F. The Green Deal, National Energy and Climate Plans in Europe: Member States' Compliance and Strategies. Adm. Sci. 2021, 11, 75. [CrossRef] 